\title{
Alternative Systems for Managing Financial Transactions in Humanitarian Crises
}

Kelbesa Megersa

Institute of Development Studies

13 April 2021

\section{Question}

- What information exists on how humanitarian actors have been able to use alternative systems for managing financial transactions, and moving money in contexts where previously well-established financial and banking systems have been disrupted by sudden shocks?

\section{Contents}

1. Overview

2. Humanitarian crises and disruptions to financial transfers (banking systems)

3. Myanmar crisis (2021 Coup) and banking disruptions

4. Beyond Myanmar: Impacts of disruptions to financial transfers in crises contexts

5. Case studies: alternative channels for financial transactions during humanitarian crisis

6. Further ways to improve financial transfers in humanitarian crises circumstances

7. References

The K4D helpdesk service provides brief summaries of current research, evidence, and lessons learned. Helpdesk reports are not rigorous or systematic reviews; they are intended to provide an introduction to the most important evidence related to a research question. They draw on a rapid deskbased review of published literature and consultation with subject specialists.

Helpdesk reports are commissioned by the UK Foreign, Commonwealth, and Development Office and other Government departments, but the views and opinions expressed do not necessarily reflect those of FCDO, the UK Government, K4D or any other contributing organisation. For further information, please contact helpdesk@k4d.info. 


\section{Overview}

Restrictions on the banking sector are having a growing adverse impact on the flow of funds to humanitarian agencies. Assisting communities affected by humanitarian crises has also become much more difficult and costly in recent years due to the complex political and logistical turmoil in crisis zones (ODI, 2021).

Delays and refusals of transactions by financial institutions or outright bank account closures worsen humanitarian crises by delaying aid distribution response times. The inability to channel funds and critical financial services into countries in humanitarian crisis (for example, due to restrictions on fund transfers, disruptions in banking and financial systems, etc.) prevents life-saving humanitarian assistance from reaching those who need it most. In the absence of legal transfer channels, the financing vacuum is often filled by illicit means, which can facilitate the spread of crime and corruption (ODI, 2021).

Humanitarian organisations have turned to a variety of transaction channels (which are sometimes less transparent), given the major disruptions in legitimate transfer mechanisms. Without these alternative money transfer channels (e.g., hawala systems and mobile money operators), humanitarian organisations will have been unable to run some parts of their programming in countries like Syria, Somalia, and Yemen (El Taraboulsi-McCarthy, 2018b).

These alternatives (sometimes desperate) means of obtaining funds will require humanitarian organisations to enter into less regulated financial agreements that are not subject to international standards. However, humanitarian agencies have fewer other options, given that they are facing serious financial difficulties. Disruptions in formal transfer channels (combined with lack of good alternative systems) are posing a threat to the delivery of help to communities in crisis zones - who are most in need of life-saving assistance (ODI, 2021).

Brief summaries of some alternative financial transfer channels used by humanitarian actors and their crisis contexts (discussed in Section 3, 4, and 5 of this report) are provided below:

\section{Myanmar:}

Transfer disruptions: humanitarian agencies are suffering from cash shortages due to transfer disruptions linked to the recent crisis (i.e., 2021 military coup). There are growing operational and financing restrictions on NGOs (e.g., Oxfam), bank closures (linked to debilitating riots), new stringent local banking regulations (especially against private banks), limits on cash withdrawals, some international transfer freezes (e.g., US), and suspension of programming and funding by donors (e.g., Japan).

Alternative transfer channels: in this new crisis, humanitarian actors so far have limited alternative channels (such as mobile/online transfers and withdrawing small amounts of cash from ATMs) to access limited amounts of financing.

\section{Syria:}

Transfer disruptions: humanitarian actors have faced significant transfer challenges and disruptions, particularly linked to stringent transfer vetting, bank de-risking, counter-terrorist financing legislations, and international sanctions. NGOs and donors have difficulties in moving cash through the correspondent banking system. Banks sometimes close the account of 
humanitarian agencies. There are also higher transaction costs linked to international financial transactions.

Alternative transfer channels: NGOs and humanitarian agencies are resorting to alternative money transfer systems such as the 'hawala' system; partnering with international NGOs to facilitate financial transfers; complementing operations with "in-kind" relief schemes; making different programming and/or organisational adaptations to better deal with the transfer disruption and cash shortages.

\section{Palestine:}

Transfer disruptions: challenging regulatory requirements on international financial transfers, linked to anti-money laundering and combating terrorist financing, have caused considerable restrictions and disruptions to humanitarian activities by NGOs in the West Bank and Gaza. Major donors particularly feel that it is better and safer to work with other international NGOs instead of working with local NGOs.

Alternative transfer channels: some local humanitarian actors and NGOs make financial transfers through non-transparent money transfer systems. Due to the relative difficulties of transacting in US dollars, humanitarian organisations alternatively use UK pounds or euros. Some NGOs also get registered in Europe so as to better access funds and link up with donors. Other alternatives, particularly by local NGOs, includes developing trust with local Palestinian organisations and using borrowed funds and other local resources. As elsewhere, humanitarian agencies have also made programming and/or organisational adaptations to endure the transfer disruptions.

\section{Yemen:}

Transfer disruptions: Bank transaction de-risking has had an adverse impact on humanitarian agencies. There are also caps on transaction size (i.e., cash withdrawals), sizeable exchange rate linked costs, and growing black-market activities.

Alternative transfer channels: the main alternative transfer channel for humanitarian agencies has been to use Yemeni money brokers (i.e., sarafeen). Although, this indirectly further weakens the formal banking systems and boosts black market trade. Other solutions include programme adaptations - e.g., around cash programming, where donors try to balance its effectiveness with the reality of limited options for cash transfers.

\section{Somalia:}

Transfer disruptions: like the above-listed countries, humanitarian actors in Somalia face stringent transfer restrictions - i.e., linked to de-risking measures by banks. Disruptions in transfers make it difficult for humanitarian agencies working within the country to receive financing via formal banking system in a timely manner.

Alternative transfer channels: because of the transfer restrictions and disruptions, humanitarian actors rely on money transfer operators; mobile banking; dedicated programmes and efforts to strengthen strict compliance rules by banks; and also adapting relief programming to better deal with (cash) transfer challenges. 
Overall, there is a relatively limited evidence base on how donors and humanitarian agencies use alternative non-bank financial transfer systems to channel humanitarian transactions - i.e., when well-established (traditional) financial and banking systems get disrupted by sudden shocks. As such, the evidence gathered from countries facing a humanitarian crisis (i.e., recent examples from Myanmar, Syria, Palestine, Yemen, and Somalia) described in Section 3, 4 and 5 are not systematically selected. Rather, the selection follows rapid reviews of available literature on (i) recent/ongoing humanitarian crisis incidents, Myanmar being purposefully included; ii) availability of some evidence on how donors and NGOs dealt with disruptions to financial transfers linked to a crisis; and (iii) following literature leads from key pieces of evidence and research projects.

The rest of the report is structured as follows. Section 2 briefly describes humanitarian crises and the associated disruptions to financial transfers (banking systems) they entail. Section 3 discusses the recent Myanmar crisis (i.e., 2021 Coup), the banking/transfer disruptions therein, how this affects humanitarian activities, what few alternative transfer options are being utilised by humanitarian actors so far. Section 4 looks at different cases of transfer disruptions and their impacts in crises contexts in other countries, namely Syria, Palestine, Yemen, and Somalia. Section 5 provides alternative and creative (sometimes unconventional and less transparent) channels for financial transactions that have been adopted by humanitarian actors - i.e., during disruptions of normal banking activities in the above-listed countries and territories. Section 6 summarises some of the key recommendations suggested by the literature to improve financial transfers in humanitarian crises circumstances.

\section{Humanitarian crises and disruptions to financial transfers (banking systems)}

\subsection{Defining 'humanitarian crisis'}

The term 'humanitarian crisis', as used in this report, adopts the typical definition by humanitarian actors - that is "an event or series of events that represents a critical threat to the health, safety, security or wellbeing of a community or other large group of people, usually over a wide area" (Tuzzolino et al., 2016: 14; Humanitarian Coalition, 2021).

\subsection{Humanitarian crises and bank/transaction disruptions}

Crisis induced disruptions to the transfer of humanitarian funds (e.g., into areas deemed to be high-risk, both for banks and for humanitarian organisations) have led to heightened due diligence requirements by banks and major donors. They have also led to extensive security checks on local humanitarian actors and implementing partners as well as greater government scrutiny of national and regional aid organisations (Fowler, 2005; McMahon, 2007; Gordon and El Taraboulsi-McCarthy, 2018).

Banks have become deeply suspicious in their dealings with NGOs and humanitarian organisations in countries engulfed by security crises. At times, accounts have been closed, and transactions have been delayed or blocked. These financial transfer disruptions within the formal international financial system have had the unintended effect of forcing greater amounts of funds through informal transfer channels, including money transfer networks like the 'hawala' system (Gordon and El Taraboulsi-McCarthy, 2018). 
For the humanitarian sector, "de-risking" by banks in crisis-affected countries and regions has become a major challenge. De-risking refers to the process where financial institutions are terminating relationships with 'high-risk' clients and closing their accounts. Money transfer service businesses, non-profit organisations, and correspondent banks have been observed de-risking, resulting in account closures - for example, in the United Kingdom, the United States, and Australia (Durner and Shetret, 2015).

When de-risking is extensively implemented (i.e., particularly against local humanitarian actors), it could further isolate vulnerable communities from the global financial system. De-risking is exacerbated by low profit, reputation damage concerns, and increased anti-money laundering and counter-terrorist financing scrutiny (Durner and Shetret, 2015).

\section{Myanmar crisis (2021 Coup) and banking disruptions}

\subsection{Crisis context}

Prior to the coup in early February 2021, nearly a million people in Myanmar depended on humanitarian aid. This number includes approximately 330,000 people who have been displaced in the country's different conflict zones. About 100,000 people are also thought to have been displaced in conflicts in northern Shan and Kachin states. These internally displaced persons (IDPs) were heavily dependent on cash aid, prior to the current crisis. The post-coup financing and cash transfer disruptions, therefore, are going to make it difficult for humanitarian agencies to help these communities (Loy, 2021). ${ }^{1}$

According to the UN World Food Programme, the near-collapse of the local banking sector, slowdown of remittances, and widespread cash shortages are exacerbating the problems of rising food and fuel prices. This is likely to increase the demand for humanitarian assistance. It is believed that the current political unrest has already started to adversely impact supply chains and markets (Nikkei Asia, 2021; Loy, 2021; Robinson and Wallace, 2021).

\subsection{Growing (humanitarian) financial transfer disruptions}

The World Bank has halted payments on withdrawal requests that were made after the coup for projects in the country. Further, funds worth 1 billion US Dollars were quickly frozen by U.S. (which are held at the Federal Reserve Bank of New York), as Myanmar's military rulers were attempting to move it shortly after seizing power (Nikkei Asia, 2021). Japan, a major donor, is also considering halting new official development aid to the country for the "foreseeable future". This is linked to the growing global outcry and pressure over the February $1^{\text {st }}$ coup and ensuing deadly crackdown on protesters by the military (Kato and Mizorogi, 2021; Nikkei Asia, 2021).

\footnotetext{
${ }^{1}$ Over the years, ethnic armed groups have fought each other or fought against the country's military - which is now responsible for the coup. Since the beginning of February 2021, new conflicts have displaced over 3,000 people, particularly in Myanmar's north and southeast regions (Loy, 2021).
} 
Nevertheless, some international aid organisations that had initially halted operations following the coup have now resumed operations, though they are still reliant on unpredictable government approvals. Local humanitarian partners are momentarily not reliant on government approval, but they are constrained by cash shortages (i.e., partly linked to transfer disruptions), fresh fighting, and the fear of being caught up in security crackdowns by the military (Loy, 2021).

Humanitarian organisations fear that disruptions in cash transfers and cash shortages could lead to a bigger issue as available financing eventually dries up. Several humanitarian agencies are already facing difficulties to pay salaries of staff, apart from programming and operational disruptions. On the other hand, humanitarian actors based in border areas rely relatively less on Myanmar's banking sector even prior to the coup. Thus, they have been able to maintain cash transfers and assistance to communities displaced in southeast Myanmar recently (Loy, 2021).

\subsection{Disruptions linked to new stifling NGO and banking regulations}

There are new restrictive orders (issued by the military regime, known as the State Administration Council (SAC)) to target specific NGOs, such as the Oxfam, the International Foundation for Electoral Systems, and Open Society Myanmar - a list that could grow further. The order warns all banks doing business with these NGOs (e.g., holding bank accounts) to carry out a financial account audit and give away the details of the audit to the authorities (Robinson and Wallace, 2021).

Commercial banks have also been ordered to disclose wide-ranging financial details of NGOs - including specific bank accounts and transactions or money transfers dating all the way back to 2016. This affects both international and local NGOs operating in the country. This discrete financial directive was issued by the Central Bank of Myanmar (Robinson and Wallace, 2021).

The military regime is exerting pressure on private banks in a variety of ways. Forced transfer of private deposit accounts to military-controlled banks is one of the threats. This is, unfortunately, hastening a reversal of the economic reforms started a decade ago (Robinson and Wallace, 2021).

\subsection{Disruptions linked to bank closures}

Banks estimate their average staffing levels to be around $20 \%$ to $30 \%$ of the pre-coup period. Bank closures have become common - as bank employees join the growing civil disobedience movement throughout the country. Low staffing has forced most banks to close their severely understaffed branches, even though many banks have tried to keep ATMs operations running (Robinson and Wallace, 2021).

Commercial banks find themselves in a tight spot since they face pressure from all sides.

- On the one hand, the regime (SAC) and Myanmar's central bank, demand them to reopen - while warning that they would seize their deposits if they remained closed. 
Following this, some commercial banks are demanding their employees to return to work. The orders to force banks to reopen their branches implies the growing unease by the SAC Government, with the worsening crisis in Myanmar's financial system and quick slide into a wider economic crisis (Robinson and Wallace, 2021).

- On the other hand, there is the civil disobedience movement that wants them to remain closed. Banks that want to open are subjected to "social shaming" by protesters on social media (Robinson and Wallace, 2021).

\subsection{Alternative channels for banking and financial transfers:}

The mass demonstrations have essentially shut down Myanmar's banking sector, making it much more difficult to transfer money into or out of the country, according to frontline aid organisations (Loy, 2021).

Humanitarian organisations and other stakeholders are increasingly relying on digital banking and ATM networks to access and transfer cash, given the disruptions in normal banking operations. However, banks are having trouble restocking ATMs with cash - due to the widespread chaos. The central bank of Myanmar has also reduced cash withdrawals from ATMs to only 500,000 kyats (USD 350) per day as from March 1st, 2021 and corporate account withdrawals to the equivalent of USD 14,000 per week.

The difficulty to move cash (and the ever-dwindling stock of cash at hand) has made it very challenging for private businesses (including foreign investors) - as well as humanitarian organisations - to pay their employees in Myanmar (Robinson and Wallace, 2021).

\section{Beyond Myanmar: Impacts of disruptions to financial transfers in crises contexts}

\subsection{Syria}

For aid agencies seeking to transfer money for humanitarian purposes into Syria, the ongoing crisis has severely limited and complicated their options. The combination of counter-terrorism financing (CTF) legislation and international sanctions has made moving and accessing funds extremely hard for humanitarian organisations. The US, the European Union, and other countries have imposed sanctions on Syria's biggest banks. Further, in places that are outside government control, the banking system has basically been destroyed (Gordon et al., 2021)..$^{2}$

Gordon et al. (2018b) discovered that bank de-risking has decreased the cash available to NGOs by at least 35 percent at any given time, and that these funds are inaccessible for longer periods of time (for three to five months, they argue) than the situation before. 
Gordon et al. (2018b) note that the main difficulties faced by humanitarian organisations have to do with:

- transferring cash via the correspondent banking system;

- the adverse effects of banks closing accounts;

- expanded and unpredictable due diligence requirements;

- bigger transaction costs linked to international financial transactions;

- the unfavourable interaction between CTF legislation and neighbouring states' legislative and regulatory arrangements (e.g., Turkey) or problems of political economy (e.g., Lebanon), and

- the difficulties of working with the informal financial sector (mainly the hawala system) in Syria.

\subsection{Palestine}

Financial access and clearance of transactions are blocked for Palestinian NGOs at international, regional, and local levels:

- Internationally: restrictions on the flow of funds to NGOs in the West Bank and Gaza have been imposed due to regulatory requirements, especially in the areas of antimoney laundering (AML) and counter-terrorist financing. This is due to the fact that several Western and Middle Eastern countries consider Hamas, which took control of Gaza after elections in 2006, to be a terrorist organisation.

- Regionally: to prevent any reputational risks associated with Hamas' presence, some Arab governments have imposed limits on the flow of funds to Palestinian NGOs.

- Locally: the Palestinian Authority in Ramallah and Hamas in Gaza impose administrative and bureaucratic burdens on local organisations, including humanitarian agencies and NGOs (El Taraboulsi-McCarthy, 2018a).

Therefore, major donors feel that it is safer to work with other international NGOs than with local NGOs - since they keep facing problems in receiving donations and grants. Competition, especially from implementing UN agencies, is another factor that is causing foreign grants (e.g., from major bilateral donors) to be diverted to international NGOs. Wide-ranging banking laws and regulatory burdens also mean that Palestinian NGOs, especially in Gaza, are unable to take the lead on development programmes and humanitarian projects or in mobilising 'best-positioned' organisations to respond to specific emergency needs of their community (El Taraboulsi-McCarthy, 2018a).

\subsection{Yemen}

In Yemen, bank transaction de-risking has had disastrous consequences for the country's humanitarian sector. International financial transfers to Yemen from US or European banks have been slowed or stopped entirely. Local transactions with the World Bank and other UN organisations were possible, but not with Yemeni stakeholders and partners 
organisations. This includes local humanitarian organisations and NGOs (El TaraboulsiMcCarthy and Cimatti, 2018).

De-risking has also led to a preference for transactions with individuals rather than organisations, according to humanitarian groups in Yemen. Some humanitarian organisations have noticed that high-profile businesspeople are able to clear transactions while NGOs are unable to do so (EI Taraboulsi-McCarthy and Cimatti, 2018).

Caps on transaction size: as per NGOs working in Yemen, it has not been easy to obtain sufficient cash to purchase items for humanitarian assistance (i.e., from local traders) due to a bank policy that does not permit the withdrawal of more than USD 5,000 out of a Yemeni bank account. NGOs note that it has been hard to make an exception to this rule, even for humanitarian activities.

Exchange rate issues: oftentimes, major donors (such as the United Nations) transfer funding to Yemen in US dollars. However, the transfer is received by beneficiaries (e.g., NGOs in Yemen) in local currency. One US dollar, for instance, is worth around 250 Riyals on paper. On the currency market, however, it is worth about 325 Riyals. The Riyal was finally floated by the Central Bank of Yemen, which the NGOs say somewhat reduced the discrepancy between official and market rates. Nevertheless, there is still a notable liquidity problem, i.e., scarcity of hard cash for humanitarian actors (El Taraboulsi-McCarthy and Cimatti, 2018).

Intensification of black-market activities: bank transaction de-risking, and the consequent restrictions on legitimate transactions, has contributed to the creation of a black-market trade, and the expansion of other cash transfer routes that rely on networks of unregulated and potentially corrupt money brokers:

- Many humanitarian groups argue that bank de-risking in Yemen has opened the door to corruption, as the lack of a functional traditional banking system has promoted the growth of other (alternative) money transfer channels that rely on unregulated and (sometimes corrupt) networks of money brokers and hawala systems (El Taraboulsi-McCarthy and Cimatti, 2018).

- Humanitarian aid can also sometimes make its way into the black market. For example, to meet immediate cash needs (i.e., because of Yemen's liquidity crisis), beneficiaries may sell relief items (EI Taraboulsi-McCarthy and Cimatti, 2018).

\subsection{Somalia}

Somalia's financial sector, which has been beset by internal and external challenges for decades, faces both internal and external challenges, all of which have significant consequences for local humanitarian actors (El Taraboulsi-McCarthy, 2018b):

- Internally: the financial sector is trapped between a small and relatively poor formal banking sector and dominant private money transfer firms.

- Externally: the implementation of counter-terrorism measures and banking legislation has resulted in transactions being postponed or frozen, and bank accounts being closed (El Taraboulsi-McCarthy, 2018b). 
These limitations on financial transactions (particularly bank de-risking measures) make it difficult for local humanitarian organisations to obtain transactions through the formal banking system in a timely manner. They also prevent money transfer operators from serving as a viable source of financial access and remittances from the Somali diaspora (EI TaraboulsiMcCarthy, 2018b).

International humanitarian and development organisations also complain that the difficulties in making transfers to local relief organisations in Somalia is causing considerable "operational difficulties" - thus, limiting their ability to respond quickly to humanitarian demands (EI Taraboulsi-McCarthy, 2018b):

- A complex web of intermediary banks and un-traceability of transactions: When humanitarian organisations send money to their partner agencies in Somalia, the procedure is often convoluted, as transfers pass through many intermediary banks before being stopped. Since humanitarian organisations do not know whether the transfers were stopped at the source bank or the intermediary bank, it's difficult for them to track it down (El Taraboulsi-McCarthy, 2018b).

- Extended delays in processing transactions: Some NGOs also say that, even though their bank accounts were not closed, transactions were often delayed or frozen for no apparent reason. Delays were normal, according to some NGOs, with some experiencing delays of up to 20 times (El Taraboulsi-McCarthy, 2018b).

- Delays have hampered the ability of non-governmental organisations (NGOs) and local humanitarian actors (particularly Islamic relief organisations) to respond. Since humanitarian organisations are often called upon to respond to conflict and natural disasters, the consequences are dire (EI Taraboulsi-McCarthy, 2018b).

- Bank de-risking limits transparency and access to formal banking: Bank de-risking has added another layer of difficulty for local humanitarian organisations already facing serious challenges in accessing international humanitarian donors. Uncertainty about the legal consequences of any form of interaction with Al-Shabaab (i.e., terrorist organisation) persists - even concerning meeting humanitarian needs (El TaraboulsiMcCarthy, 2018b).

\section{Case studies: alternative channels for financial transactions during humanitarian crisis}

\subsection{Syria}

Humanitarian actors and NGOs have resorted to various alternative transfer channels and coping mechanisms to deal with limited financial access, in the face of transfer restrictions by banks.

\section{Resorting to alternative money transfer system (hawala):}

The hawala scheme has made it much easier and safer to transfer cash across conflict zones. However, several NGOs in Syria note that the hawala system was also by far the most difficult strategy to explain to banks, even if major (western) donors were generally aware of what was going on (Gordon et al., 2018). 
Some of Syria's larger NGOs tried to properly identify their hawala operators, supplier firms, and partner entities within the country. The identification of these "safe groups and partners" helped humanitarian agencies to safely maintain long-term relationships, easing costly scrutiny of transactions by banks. The finance directors of NGOs also made sure that they got receipts for each transaction. Knowing the identities of those involved in the transaction network particularly pleased banks - thus, reducing transfer restrictions and blockages (Gordon et al., 2018).

\section{Partnering with western/international NGOs to facilitate transfers:}

Transactions involving money from European international NGOs are much more likely to pass through the international financial system than donations from somewhere else - e.g., such as the Middle East (Gordon et al., 2018).

\section{Resorting to "in-kind" relief schemes:}

Several smaller NGOs have also used their own version of hawala systems to exchange in-kind relief goods and currency. While this administrative mechanism enabled humanitarian organisations to pay for cash transactions as if they were in-kind donations, the audit trail was clearly obfuscated. In some cases, NGOs actually disguised cash movements by requesting inkind humanitarian assistance (e.g., food parcels). NGOs used the hawala scheme to transfer money as well, but they prepared receipts that looked like food baskets. These (in-kind) resource exchanges are made both within NGO networks and between larger and more developed NGOs' country offices (Gordon et al., 2018).

\section{Programming and/or organisational adaptations:}

NGO priorities have shifted in a subtle but noticeable way as they systematically moved away from funding cash-based initiatives to prevent delays in the flow of funds (Gordon et al., 2018), even though cash-based programmes were often seen as key enablers for activities that had the potential to support the most marginalised communities in conflict zones (Gordon et al., 2018; Derzsi-Horvath et al., 2017).

Humanitarian organisations and NGOs have had to change their programming due to significant disruptions to the conventional banking system in Syria, i.e., since the conflict. Many humanitarian actors have since shifted their focus away from cash-based programs and toward in-kind assistance. Because banks often block money when it has a large cash portion to be spent within Syria, NGO's have been forced to abandon cash programming. These restrictions have, for example, made it nearly impossible for NGOs to buy fuel or pay salaries to local workers (Gordon et al., 2018).

Syrian NGOs and humanitarian actors that succeed in moving transactions appeared to be those that:

- $\quad$ are the largest, most established, and those that had developed strong subcontracting relationships (especially with major European NGOs);

- who made the most conservative programming decisions;

- who had invested heavily in "compliance" activities and operated in more secure areas, expectedly felt the least impacted (Gordon et al., 2018). 
Humanitarian actors and NGOs were able to avoid problem jurisdictions and transfer funding by:

- working more strategically and by pre-planning for the movement of funds through the banking system;

- making use of local networks and other internal budgets to discover alternative sources of funds;

- building trust with banks;

- encouraging donors to change the currencies being transferred (e.g., transacting in euro or sterling, rather than US dollars);

- switching/exploring different banks and sending money through indirect banking routes;

- transferring money in 'numerous but smaller' transactions - with each one potentially being routed through different institutions and countries;

- transferring relief into programme areas through commodity-based assistance and cash-commodity exchanges with other NGOs (Gordon et al., 2018).

There was no single method, however, that guaranteed financial transfer - and most of the above alternatives were still difficult to implement. For instance:

- When exchanging money in euros there were still significant delays and requests for 'more' information by banks, even though these requests were often less onerous than when dealing with transactions in dollars (Gordon et al., 2018).

- Government donors and the UN, in general, would usually not allow money to be moved in any currency other than the one in which they did their business with, which often was US dollars (Gordon et al., 2018).

- Sending money in smaller sums was time-consuming and inconvenient procedure for the NGOs. On one occasion, a Turkish NGO was forced to transfer stalled funds worth USD 1.2 million (from its European donor) through several individual transactions totalling less than USD 50,000 (Gordon et al., 2018).

Usually, international donors do not cover the fees associated with the subsequent (higher) currency exchange charges on international transfers. These fees are often borne by the recipient NGOs and humanitarian actors in the crisis country. Commission fees vary widely, ranging from 2.5 percent to 30 percent. Syrian NGOs have also stated attempting to open several bank accounts in order to avoid being de-risked by any of their banks, further increasing costs and staff time commitments. This was seen as having a significant impact on NGOs' finances and program feasibility, particularly when combined with the costs of moving cash via Syria's money transfer network (Gordon et al., 2018).

\subsection{Palestine}

\section{Resorting to alternative money transfer system (opaque):}

Due to financial access limits, NGOs are forced to use less transparent networks to move funds. That is, financial transactions between NGOs were forced to be done "under the table." Since 
institutional bank accounts are blocked, this usually meant transactions with cash in hand or transfers to personal bank accounts of NGO workers. As a result, transactions were often made through an intermediary, such as a board member or another individual who could be trusted (El Taraboulsi-McCarthy, 2018a).

To prevent delays, some Palestinian humanitarian organisations opened bank accounts for their project's suppliers and contractors, allowing them to collect payments and wages directly rather than through NGOs (El Taraboulsi-McCarthy, 2018a).

\section{Curbing US dollar-based transactions (at a cost):}

Since making and obtaining transfers in US dollars is difficult, some humanitarian organisations have requested transfers in other currencies, such as the UK pound or the euro. Currency fluctuations, as previously stated, can result in financial losses, and can also cause uncertainty when project contracts are priced in US dollars. According to El Taraboulsi-McCarthy (2018a), one international humanitarian organisation lost around USD 50,000 when converting dollars to euros and then back to dollars - since all project contracts were in dollars.

\section{Registering NGOs in western countries:}

Some humanitarian organisations have registered in Europe in order to gain access to funds and donors, as well as to facilitate transactions between foreign banks and Palestinian banks. NGOs also found out that banks had fewer issues with their transfers when they worked through European-registered organisations (El Taraboulsi-McCarthy, 2018a).

\section{Developing trust with local organisations:}

Many local humanitarian actors seemed to depend on community cohesion and confidence as a safety net. The presence of confidence (e.g., between humanitarian NGOs and local suppliers) encourages local organisations (i.e., supplier businesses) to be patient and wait for delayed funds (i.e., NGO funds stuck in transit) to arrive and be deposited in local bank accounts (EI Taraboulsi-McCarthy, 2018a).

\section{Using borrowed funds and local resources:}

Palestinian NGOs in the West Bank and Gaza have sometimes resorted to borrowed funds and local capital in the absence of financial access. Unfortunately, due to the scarcity of local capital, this is not a viable and scalable option (El Taraboulsi-McCarthy, 2018a).

\section{Programming and/or organisational adaptations:}

Due to the difficulties in sending funds to and from Gaza, humanitarian organisations have had to change their programming to accommodate the restrictions. This may result in changes to original programme priorities, timelines, programme scale and scope - or, in the worst-case scenario, lead to programme suspension (El Taraboulsi-McCarthy, 2018a).

Donors regard cash assistance as especially risky in light of global counter-terrorism efforts, so it has become extremely restricted. This is because recipients will have greater flexibility 
in how they use the money - including for unintended purposes (El Taraboulsi-McCarthy, 2018a).

\subsection{Yemen}

\section{Resorting to alternative money transfer system (money brokers/sarafeen or hawala):}

- It was noted that 'sarafeen' (Yemeni money brokers) have grown rapidly in response to restrictions on formal bank transactions - and have now become the primary source of cash distribution both locally and internationally. As a result, moving cash around without 'sarafeen' has become impossible for humanitarian organisations and other actors (El Taraboulsi-McCarthy and Cimatti, 2018).

- Some humanitarian actors, nevertheless, note that illicit transactions in food and fuel are taking place in the black market often because of the weakening of the banking system (El Taraboulsi-McCarthy and Cimatti, 2018).

\section{Programming and/or organisational adaptations:}

Challenges to cash transfer programming: As a result of the de-risking process, humanitarian organisations' ability to inject cash into Yemen has been restricted. Although evidence indicates that cash transfer programs can and should be prioritised in humanitarian crises, their full potential has yet to be realised. Cash programming encourages beneficiaries to prioritise their needs, and locally invested cash leads to market recovery and livelihood reestablishment (IIED, 2016; El Taraboulsi-McCarthy and Cimatti, 2018).

Local humanitarian organisations and communities are eventually figuring out how to work around de-risking and continue their humanitarian response operations - even in the face of adversity - by focusing on locally sourced funds and services, as well as thinking creatively about how to ensure that humanitarian aid reaches those in need (EI Taraboulsi-McCarthy and Cimatti, 2018).

\subsection{Somalia}

\section{Resorting to alternative money transfer system (money transfer operators and mobile banking):}

Because local humanitarian organisations are unable to rely on banks for their transactions, they are forced to switch to either money transfer operators (MTOs) or mobile banking. By one estimate, more than $70 \%$ of the Somali population uses unregulated mobile money, which is apparently effective. As a result, MTOs and mobile banking are critical components of the country's humanitarian response (El Taraboulsi-McCarthy, 2018b).

Based on her research and interviews with bankers, academics, and especially humanitarian actors in Somalia, El Taraboulsi-McCarthy (2018b) points to the following: 
- Money transfer businesses, mobile money, and other methods of financial transactions that are outside the formal banking system are crucial to the humanitarian response in Somalia.

- The increasing acceptance of MTOs among the population may has undermined and weakened the Central Bank of Somalia - since it has no control over these non-bank money transfer businesses.

- The majority of local and international MTOs seem to have adopted rigorous 'Know Your Customer' measures. Nevertheless, some local money transfer businesses have questionable transparency standards and have led to aid diversion (El TaraboulsiMcCarthy, 2018b).

\section{Better compliance to stringent bank regulations:}

Many humanitarian organisations have improved their compliance standards or other internal processes to deal with bank de-risking (for security reasons) in order to prevent aid from being diverted (El Taraboulsi-McCarthy, 2018b; Modirzadeh, 2013).

Some international humanitarian organisations have also discontinued the use of some MTOs (especially those with poor transparency standards) in order to promote greater financial and aid transparency. Nonetheless, since many local humanitarian organisations lack access to bank accounts, they are unable to efficiently use these funds (EI Taraboulsi-McCarthy, 2018b).

According to El Taraboulsi-McCarthy (2018b), a counter-terrorism regime that prioritises enforcement over humanitarian imperatives has an effect on local humanitarian organisations' access to open, structured banking service. MTOs are the de facto banks in Somalia, according to humanitarian agencies. As such, the difficulty of transferring money externally via the formal/traditional banking system has forced humanitarian actors to work with MTOs.

\section{Programming and/or organisational adaptations:}

International humanitarian organisations in Somalia note that the majority of their cash programming is now done through hawala companies or MTOs with bank accounts in the United States, Europe, or the Gulf region, especially Dubai. As a result, if MTOs lose access to banking arrangements, their ability to implement cash transactions locally would be jeopardised (EI Taraboulsi-McCarthy, 2018b). ${ }^{3}$

Recent digital financial tools like cards and mobile-based money transfers have the potential to facilitate and expand cash delivery during humanitarian crises - while at the same time lowering management and security costs. They offer beneficiaries more power of how and when they spend their money than in-kind help. Nevertheless, pay-point infrastructure (including agents, merchants, and/or ATMs) is still needed. Account-based digital cash transfers could improve aid recipients' financial participation by allowing them to establish a banking track record and allowing financial service providers to give them additional financial products as clients. Cash

\footnotetext{
${ }^{3}$ In order to cope with severe delays, some humanitarian organisations have called on Somalis in the diaspora to send funds through the hawala system, rather than through banks. Another alternative is to borrow money locally (El Taraboulsi-McCarthy, 2018b).
} 
recipients' ability and interest in using digital accounts, on the other hand, differs greatly across contexts (Tuzzolino et al., 2016).

\section{Further ways to improve financial transfers in humanitarian crises circumstances}

International humanitarian actors, according to El Taraboulsi-McCarthy and Cimatti (2018b), should take a holistic approach to crisis zones, combining humanitarian, economic, and security considerations rather than working in a fragmented manner. The crises in Yemen, Syria, and Somalia, for example, demonstrate the importance of a holistic approach to humanitarian relief, development, and security.

Cash transfer programming may also be a way to connect the humanitarian response to a post-conflict reconstruction plan and the resumption of economic activities. To promote the flow of funds to meet humanitarian and economic reconstruction needs, a change in existing de-risking policy might be needed. A stronger and revamped Central Bank could function as a guarantee that funds are used for legal purposes (El Taraboulsi-McCarthy and Cimatti, 2018b). However, this will prove to be difficult in countries where the Central Bank has always been weak or incapacitated following major conflict incidents and market disruptions.

El Taraboulsi-McCarthy (2018a) recommends that international NGOs (e.g., those in Europe) should join forces with NGOs from the global South to campaign for consistent financial legislation and flexible support for local humanitarian and development organisations. She claims that global pressure to resolve the negative implications of counter-terrorism and bank de-risking has yet to be meaningfully established. A coalition of organisations and foundations from the global North and South is needed to make a case for proportionately controlling the market, rather than in a manner that makes vulnerable people in crisis countries even more vulnerable.

Gordon et al. (2018b) warn that much needs to be done to strike a better balance between i) properly vetting financial transfers and ii) the unintended humanitarian consequences of transfer disruptions - especially to the humanitarian sector.

Gordon et al. (2018b) further note that humanitarian actors and banks widely agree on the reforms that could enhance the regulatory system's effectiveness from both a humanitarian and a CTF viewpoint. Some of these reforms imply that:

- Banks and NGOs agree on a code of conduct - regarding what constitutes sufficient compliance and transparency in terms of systems and recordkeeping, and the exemptions that are possible in the very difficult situations.

- Banks approve a due diligence code of conduct on the types of regularly required types and what is considered 'sufficient' information. Banks make this code of conduct accessible to the humanitarian community.

- Donors acknowledge the higher overhead costs associated with operating in countries in conflict and commit to cover these costs for local NGOs.

- Donors make an agreement to be more accommodating with the currencies used in transactions. 
- Hawala transfer channels are put on a clearer regulatory foundation in circumstances where they are the only viable options of moving money into areas of significant humanitarian need.

- The creation of a mechanism for approving a list of acceptable or 'safe' organisations from which NGOs can purchase supplies and commodities, as well as with which they can conduct financial transactions.

- The creation of an international humanitarian financial clearing system to complement the role of correspondent banks.

\section{References}

Derzsi-Horvath, A., Steets, J., \& Ruppert, L. (2017). Independent Grand Bargain Report. Global Public Policy Institute and Inspire Consortium.

https://interagencystandingcommittee.org/system/files/nn_-_grand_bargain_report_final.pdf

Durner, T., \& Shetret, L. (2015). Understanding bank de-risking and its effects on financial inclusion: An exploratory study. https://www.globalcenter.org/wp-content/uploads/2015/11/rrbank-de-risking-181115-en.pdf

El Taraboulsi-McCarthy, S. (2018a). 'A humanitarian sector in debt' Counter-terrorism, bank derisking and financial access for NGOs in the West Bank and Gaza. HPG Working Paper. Humanitarian Policy Group. https://cdn.odi.org/media/documents/12357.pdf

El Taraboulsi-McCarthy, S. (2018b). The Challenge of Informality. Counter-terrorism, Bank Derisking and Financial Access for Humanitarian Organisations in Somalia.

https://cdn.odi.org/media/documents/12258.pdf

El Taraboulsi-McCarthy, S., \& Cimatti, C. (2018). Counter-terrorism, de-risking and the humanitarian response in Yemen: a call for action. HPG Working Paper. Humanitarian Policy Group. https://cdn.odi.org/media/documents/12047.pdf

Fowler, A. (2005). Aid Architecture Reflections on NGDO Futures and the Emergence of Counter-Terrorism. Occasional Papers Series, 45. INTRAC.

https://www.researchgate.net/publication/245236135_Aid_Architecture_Reflections_on_NGDO_ Futures_and_the_Emergence_of_Counter-Terrorism/link/0deec53cd04f80fbac000000/download

Gordon, S., \& El Taraboulsi-McCarthy, S. (2018). Counter-terrorism, bank de-risking and humanitarian response: a path forward. Humanitarian Policy Group Policy Brief, 72.

https://cdn.odi.org/media/documents/12368.pdf

Gordon, S., Robinson, A., Goulding, H., \& Mahyub, R. (2018). The impact of bank de-risking on the humanitarian response to the Syrian crisis. HPG Working Paper. Humanitarian Policy Group. https://cdn.odi.org/media/documents/12376.pdf

Gordon, S., Robinson, A., Goulding, H., \& Mahyub, R. (2021). The impact of bank de-risking on the humanitarian response to the Syrian crisis. Overseas Development Institute.

https://odi.org/en/publications/the-impact-of-bank-de-risking-on-the-humanitarian-response-tothe-syrian-crisis/ 
Humanitarian Coalition (2021). What Is a Humanitarian Emergency?

http://humanitariancoalition.ca/info-portal/factsheets/what-is-a-humanitarian-emergency

Kato, M. and Mizorogi, T. (2021). 'Japan set to halt new Myanmar assistance following coup'. Nikkei Asia. (Visited Apr 02, 2021) https://asia.nikkei.com/Spotlight/Myanmar-Coup/Japan-setto-halt-new-Myanmar-assistance-following-coup

Loy, I. (2021). 'Post-coup cash shortages put pressure on Myanmar aid'. The New Humanitarian. (Visited Apr 02, 2021). https://www.thenewhumanitarian.org/news-feature/2021/3/2/myanmarcoup-cash-shortages-pressure-on-aid-to-conflict-zones

McMahon, J. (2007). Developments in the regulations of NGOs via government counter-terrorism measures and policies. Policy Briefing Paper, 11. INTRAC. https://www.intrac.org/wpcms/wpcontent/uploads/2016/09/Briefing-Paper-11-Developments-in-the-regulation-of-NGOs.pdf

Modirzadeh, N. (2013). Counter-terrorism and Humanitarian Engagement in Somalia and Mali. Harvard Blogs. http://blogs.harvard.edu/cheproject/files/2012/10/CHE-Project-Somalia-andMali.pdf

Nikkei Asia (2021). 'Myanmar coup: Week from Feb. 20 to March 18, UN team urges whistleblowers to report illegal orders'. Nikkei Asia. (Visited Apr 02, 2021) https://asia.nikkei.com/Spotlight/Myanmar-Coup/Myanmar-coup-Week-from-Feb.-20-to-March18-UN-team-urges-whistleblowers-to-report-illegal-orders

ODI (2021). Understanding the impact of de-risking on humanitarian aid. Overseas Development Institute. https://odi.org/en/about/our-work/understanding-the-impact-of-de-risking-onhumanitarian-aid/

Robinson, G. and Wallace, R. (2021). 'Myanmar junta targets banks in push against 'foreign interference”. Nikkei Asia. (Visited Apr 02, 2021) https://asia.nikkei.com/Spotlight/MyanmarCoup/Myanmar-junta-targets-banks-in-push-against-foreign-interference

Tuzzolino, Y., Hansen, L., \& Juillard, H. (2016). Cash Transfer Resilience Tool. International Rescue Committee. https://seepnetwork.org/files/galleries/1732_CRTC-Handbook-Finalrevision.pdf 


\section{Suggested citation}

Megersa, K. (2021). Alternative Systems for Managing Financial Transactions in Humanitarian Crises. K4D Helpdesk Report 993. Brighton, UK: Institute of Development Studies.DOI:10.19088/K4D.2021.136

\section{About this report}

This report is based on six days of desk-based research. The K4D research helpdesk provides rapid syntheses of a selection of recent relevant literature and international expert thinking in response to specific questions relating to international development. For any enquiries, contact helpdesk@k4d.info.

K4D services are provided by a consortium of leading organisations working in international development, led by the Institute of Development Studies (IDS), with Education Development Trust, Itad, University of Leeds Nuffield Centre for International Health and Development, Liverpool School of Tropical Medicine (LSTM), University of Birmingham International Development Department (IDD) and the University of Manchester Humanitarian and Conflict Response Institute (HCRI).

This evidence summary was prepared for the UK Government's Foreign, Commonwealth and Development Office (FCDO) and its partners in support of pro-poor programmes. It is licensed for non-commercial purposes only. Except where otherwise stated, it is licensed for non-commercial purposes under the terms of the Open Government Licence v3.0. K4D cannot be held responsible for errors, omissions or any consequences arising from the use of information contained in this health evidence summary. Any views and opinions expressed do not necessarily reflect those of FCDO, K4D or any other contributing organisation.

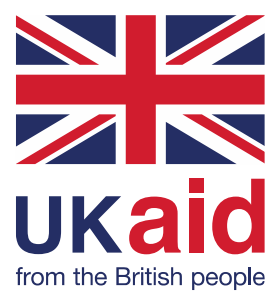

(C) Crown copyright 2021. 